\title{
Solving Transportation Problem with the help of Integer Programming Problem
}

\author{
Gaurav Sharma $^{1}$ S. H. Abbas ${ }^{2}$ Vijay kumar Gupta ${ }^{3}$ \\ ${ }^{I}$ Deptt. of mathematics, IES institute of technology and Mangment, Bhopal(M.P.) \\ ${ }^{2}$ Deptt. of mathematics, Saifia Science college Bhopal(M.P.). \\ ${ }^{3}$ Deptt. of mathematics, UIT, RGPV Bhopal(M.P.)
}

\begin{abstract}
The Transportation Problem is one of the subclass of linear programming problem which the objective is to minimize transportation cost of goods transport to various origins to different destinations. In this paper we are representing the transportation problem for Albert David Company to reduce transportation cost, its working with 3 plants and 14 depots in all over India. In [6][7] we are solve the transportation problem with the help of dual simplex and two phase method. Here we are solving this problem with the help of Branch and Bound Method of Integer programming Problem by using Tora software and we are comparing the obtained optimal solution with Vogel Approximation Method.
\end{abstract}

Key Words: - Transportation Problem, Integer Programming Problem, Branch and Bound Method

\section{INTRODUCTION}

Transportation Problem is one of the fundamental problems of network flow problem which is usually use to minimize the transportation cost for industries with number of sources and number of destination while satisfying the supply limit and demand requirement. Transportation Problem firstly presented by F. L. Hitchcock [1] in his paper "The Distribution of a Product from Several sources to numerous Localities" and after that it's presenting by T. C. Koopmans [2] in his historic paper "Optimum Utilization of the Transportation System". These two contributions helped in the development of transportation methods which involve a number of shipping sources and a number of destinations. In the recent past, Transportation Problem with a different single objective to minimize the duration of transportation has been studied by many researchers such as Sharma and Swarup [8], Seshan and Tikekar[5], Prakash, Papmanthou[4],and Sonia, Sonia et al[10] studied on time transportation problem. Surapati and Roy [11], Wahead and Lee [12] and Zangibadi and Maleki [13] presented a fuzzy goal programming approach to determine an optimal solution for the multi-objective transportation problem etc.

In this paper we change the transportation problem in Integer programming problem and solving this problem by Branch and Bound Method with tora software.

\section{Formulation of Transportation problem in Linear Programming Problem}

Given $\mathrm{m}$ origins and $\mathrm{n}$ destinations, the transportation problem can be formulated as the following linear programming problem model:

Minimize: $\quad \sum_{i=1}^{m} \sum_{j=1}^{n} c_{i j} x_{i j}$

Subject to constraint:

$$
\begin{array}{ll}
\sum_{j=1}^{n} x_{i j} \leq a_{i} & \mathrm{i}=1,2, \ldots \ldots \ldots \ldots \mathrm{m} \\
\sum_{i=1}^{m} x_{i j} \geq b_{j} & \mathrm{j}=1,2, \ldots \ldots \ldots \ldots \mathrm{n} \\
x_{i j} \geq 0 &
\end{array}
$$

for all $\mathrm{i}$ and $\mathrm{j}$

Where $x_{i j}$ is the amount of units of shipped from origin I to destination $\mathrm{j}$ and $c_{i j}$ is the cost of shipping one unit from origin $\mathrm{i}$ to destination $\mathrm{j}$. The amount of supply at origin is ai and the amount of destination $\mathrm{j}$ is bj. The objective is to determine the unknown xij that will the total transportation cost while satisfying all the supply and demand constraints 


\section{Numerical Example}

Tables and Figures

Next table 1 represents the quantity available these factory (Plant's) for a month

Table 1

\begin{tabular}{|l|l|}
\hline factory(Plant's) & Supply \\
\hline Madideep(A) & 20 Truck \\
\hline Gajiabad(B) & 50 Truck \\
\hline Calcutta(C) & 50 Truck \\
\hline Total & 120 \\
\hline
\end{tabular}

Next table 2 represents the total demand of the warehouses in various places. These supplies for a month

Table 2

\begin{tabular}{|l|l|}
\hline Warehouses & Demand \\
\hline Bhopal(X) & 10 \\
\hline Raipur(Y) & 06 \\
\hline Mumbai(Z) & 14 \\
\hline Total & 30 \\
\hline
\end{tabular}

\section{Formulation and Tables}

In this problem we make a transportation problem for Albert David Company as being the essential commodity. We get the following transportation model to determine an optimal solution so as to minimize the transportation cost.

\section{Table 3}

(A)

$$
\text { (X) }
$$

(X) \begin{tabular}{|l|l|l|l|}
\multicolumn{1}{c}{$(\mathrm{Y})$} & $(\mathrm{Z})$ & \multicolumn{1}{c|}{ Capacity } \\
\hline 8 & 10 & 20 & 20 \\
\hline 40 & 30 & 55 & 50 \\
\hline 20 & 25 & 35 & 50 \\
\hline 10 & 6 & 14 & \\
\hline
\end{tabular}

Demand

(B)

(C)

Here $\Sigma \mathrm{a}_{\mathrm{i}}=120, \quad \Sigma \mathrm{b}_{\mathrm{j}}=30$. since $\Sigma \mathrm{a}_{\mathrm{i}} \neq \Sigma \mathrm{b}_{\mathrm{j}}$, we introduce the dummy warehouse "D" with the demand 90 trucks and zero transportation cost, as shown in the next table in the form of balanced transportation problem:- 
Table 4

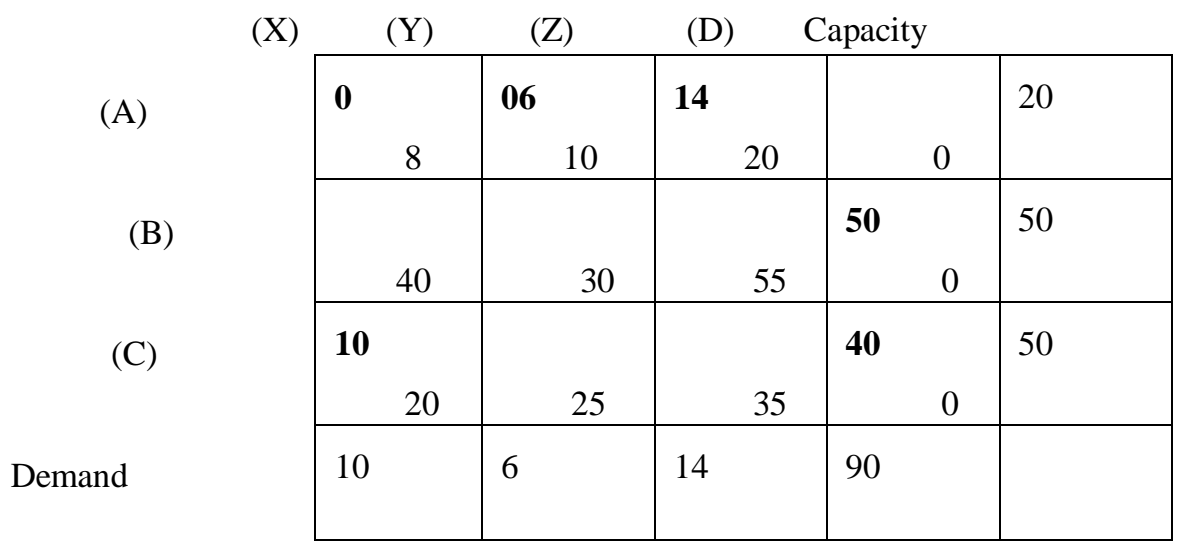

From VAM method, we find number of occupied cells are 6 which is equal to $m+n-1$.Then solution as

$$
X_{11}=0 \quad X_{12}=06 \quad X_{13}=14 \quad X_{24}=50 \quad X_{31}=10 \quad X_{34}=40
$$

The associative objective function value (transportation cost) is Rs 540,000

\section{Linear Programming Problem Formulation of Transportation Problems}

Now we are converting the transportation problem in Linear programming problem by using table 4

Minimize: $Z=8 X_{11}+10 X_{12}+20 X_{13}+40 X_{21}+30 X_{22}+55 X_{23}+20 X_{31}+25 X_{32}+35 X_{33}$

Subject to constraint: $\quad \mathrm{X}_{11}+\mathrm{X}_{12}+\mathrm{X}_{13} \leq 20$

$$
\begin{aligned}
& \mathrm{X}_{21}+\mathrm{X}_{22}+\mathrm{X}_{23} \leq 50 \\
& X_{31}+X_{32}+X_{33} \leq 50 \text {. } \\
& \mathrm{X}_{11}+\mathrm{X}_{21}+\mathrm{X}_{31} \geq 10 \\
& \mathrm{X}_{12}+\mathrm{X}_{22}+\mathrm{X}_{32} \geq 6 \text {. } \\
& X_{13}+X_{23}+X_{33} \geq 14 \\
& \mathrm{X}_{11}, \mathrm{X}_{12}, \mathrm{X}_{13}, \mathrm{X}_{21}, \mathrm{X}_{22}, \mathrm{X}_{23}, \mathrm{X}_{31}, \mathrm{X}_{32}, \mathrm{X}_{33} \geq 0
\end{aligned}
$$

Firstly we change the problem in integer programming problem and using Tora Software on Integer Programming Formulation of Transportation Problem we are getting the optimal solution of our transportation problem which solving for Albert David Company to reduce transportation cost Rs 540,000 at $X_{12}=6, X_{13}=14, X_{31}=10$

\section{Conclusion}

We have established the uniqueness and existence of optimal solution of the transportation problem for Albert David Company. This has been brought out through developed transportation problem into integer programming problem and applying the discuss methods in paper which yields the same optimal solution and have stated the optimality conditions of the problem. And we get Branch and Bound method gives the same result with respect to VAM.

\section{REFERENCES:}

1. Hitchcock, F. L. "The distribution of product from several source to numerous localities", J. Maths. Phy. ,vol 20, (1941), pp 224-230

2. Koopman, T.C. "Optimum utilization of transportation system”, Proc. Intern. Statics. Conf. Washington D.C., (1947)

3. Prakash, S. "On minimizing the duration of transportation", Proceedings of the Indian Academy of SciencesMathematical Sciences, Vol. 91, ( 1982), pp53-57

4. Papamanthou, C., Paparrizos, K., Samaras N. "Computational experience with exterior point algorithms for the transportation problem", Applied Mathematics and Computation, Vol. 158, (2004), pp459-475

5. Seshan, C. R., Tikekar, V. G. " On the Sharma Swaup algorithm for time minimizing transportation problems”, Proceeding of Indian Academy of Sciences Mathematical Science, Vol. 89, (1980), pp 101-102 
6. Sharma, Gaurav; Abbas, S. H.; Gupta, Vijay“Optimum Solution of Transportation Problem with the help of phase-II method of Simplex Method", Indian journal of applied life science, Vol. 6, No. 1 \& 2, (2011), pp 4954

7. Sharma, Gaurav; Abbas, S. H.; Gupta, Vijay "Dual Simplex Algorithm for Proctor \& Gamble to Solve Transportation Problem", Journal of Ultra Scientist of Physical Sciences, vol. 23, No. 2, (2011)

8. Sharma, J.K., Swarup, K. "Time minimizing transportation problem", Proceedings of Indian Academy of Sciences-Mathematical Sciences, Vol. 86, ( 1977), pp513-518

9. Sonia, Khandelwal, A., Puri, M.C. "Bilevel time minimizing transportation problem", Discrete Optimization, Vol. 5, No.4, ( 2008), pp714-723

10. Sonia, Puri, M.C. "Two level hierarchical time minimizing transportation problem", Top, Vol. 12, No.2, ( 2004), pp301-330,

11. Surapati, P. and Roy, T. K. "Multi-objective transportation model with fuzzy paparmeters: Priority based fuzzy goal programming approach", Journal of Transportation Systems Engineering and Information Teachnology, Vol. 8, (2008) pp 40-48

12. Wahead, W. F. and Lee, S. M. "Interactive fuzzy goal programming problem for multi-objective transportation problem", Omega, Vol. 34, (2006) pp 158-166

13. Zangibadi, M and Maleki, H. R. "Fuzzy goal programming for multi-objective transportation problem", Applied Mathematics and Computation, Vol. 24, (2007), pp 449-460 